\title{
STATUS SOSIAL EKONOMI PETERNAK KAMBING PERANAKAN ETAWA (PE) DI DESA SUNGAI LANGKA, KECAMATAN GEDONG TATAAN, KABUPATEN PESAWARAN PROVINSI LAMPUNG
}

\author{
Social Economics Status of Farmer Groups Ettawa Crossbred Goat in Sungai Langka Village, \\ Gedong Tataan District, Pesawaran Regency, Lampung Province
}

\author{
Tri Rumiyani ${ }^{a}$ dan M. Dima Iqbal Hamdanib \\ aDepartment of Animal Husbandry, Polytechnic State of Lampung \\ ${ }^{b}$ Department of Animal Husbandry, Lampung University \\ email : tri3rumiyani@gmail.com
}

\begin{abstract}
The aim of this research was to know social economic status of farmer groups Ettawa crossbred goat during the production and cost value of the milk. The research was held on July - August 2016 in Ettawa farmer groups in Sungai Langka Village, Gedong Tataan District, Pesawaran Regency, Lampung Province. Material of this research were 40 samples from three farmer groups : Tunas Muda, Sehati jaya and Margarini 6. The method of this research was a survey with purposive random sampling. Data were analyzed by descriptive analysis. The result showed each farmer groups had different social economic status during production and cost value of the milk.
\end{abstract}

Keywords : Ettawa Crossbred Goat, Social Economic Status, Sungai Langka Village.

\section{PENDAHULUAN}

Provinsi Lampung merupakan daerah yang memiliki potensi untuk pengembangan usaha peternakan. Ternak kambing memiliki potensi sebagai komponen usaha tani yang penting pada berbagai agroekosistem karena memiliki kemampuan adaptasi yang relative lebih baik dibandingkan dengan ternak ruminansia lain (Ginting 2009 dalam Asmara et $a l, 2013)$.

Pada tahun 2010, populasi kambing di provinsi lampung mencapai 997.412 ekor dan pada tahun 2011 meningkat menjadi 1.090.647 ekor (Dinas Peternakan dan Kesehatan Hewan Provinsi Lampung, 2011). Desa Sungai Langka, Kecamatan Gedong Tataan, Kabupaten Pesawaran, Provinsi Lampung merupakan wilayah pedesaan yang sebagian besar masyarakatnya memelihara kambing Peranakan Etawa (PE) sebagai usaha sambilan.Populasi kambing yang ada di Kabupaten Pesawaran mencapai 28.787 ekor (Dinas Peternakan dan Kesehatan Hewan Provinsi Lampung, 2011). Mata pencaharian penduduknya kurang lebih 90\% sebagai petani kakao dan memelihara kambing sebagai usaha sambilan. Lahan yang ditanami kakao kurang lebih 600 ha dan menghasilkan kulit buah kaako untuk pakan kambing khususnya kambing PE (Pemerintah Daerah Kabupaten Pesawaran,2009).
Produksi susu kambing PE yang di hasilkan di desa Sungai Langka ,Kecamatan Gedong tatan, Kabupaten Pesawaran sudah mulai dikonsumsi oleh masyarakat di berbagai daerah di Provinsi Lampung. Hasil penjualan susu kambing PE di daerah ini dapat meningkatkan pendapatan pokok dari pertanian tanaman kakao. Pertambahan pendapatan pokok ini mengindikasi bahwa adanya peningkatan kesejahteraan bagi peternak kambing PE. Peningkatan kesejahteraan peternak dapat di teliti untuk mengetahui status sosial ekonomi peternakan kambing PE di desa Sungai Langka Kecamatan Gedong tataan, Kabupaten Pesawaran.

\section{MATERI DAN METODE}

\section{Lokasi}

Penelitian akan dilaksanakan pada bulan Juli - Agustus 2016 di kelompok ternak Kambing PE di Desa Sungai Langka, Kecamatan Gedogtataan Kabupaten Pesawaran, Provinsi Lampung.

\section{Materi}

Materi penelitian yang digunakan adalah peternak kambing PE di desa Sungai Langka, Kecamatan Gedong tataan Kabupaten Pesawaran. Dari jumlah 55 peternak Kambing PE di tiga kelompok (Tunas Muda, Sehati jaya 
dipilih 40 peternak yang mewakili 3 kelompok ternak tersebut sebagai sampel penelitian. Masing -masing 18 peternak dari 25 peternak di kelompok ternak Tunas Muda, 13 peternak dari 18 peternak di kelompok ternak Sehati Jaya dan 9 peternak dari 12 peternak di kelompok ternak Margarini 6.

\section{Metode}

Penelitian ini menggunakan metode survey data yang diambil adalah data primer dan sekunder. Data primer di lakukan dengan mewawancarai peternak dengan menggunakan Kuisioner dan data sekunder data yang diambil dari instansi terkait. Cara pengambilan data dilakukan secara purposive random sampling yaitu masing-masing kelompok ternak diambil sampel yang mewakili kelompok ternaknya. Wawancara secara personal kepada kepala rumah tangga peternak kambing PE yang terpilih sebagai responden dan dipandu dengan kuesioner berisi beberapa pertanyaan baik yang bersifat tertutup maupun yang bersifat terbuka (closed and open-ended questions). Anggota keluarga juga boleh menjawab pertanyaan untuk melengkapi informasi yang diberikan oleh kepala rumah tangga.

\section{Analisis Data}

Data yang diperoleh dianalisis menggunakan analisis deskriptif.

\section{Parameter Penelitian}

Parameter penelitian meliputi karakteristik rumah tangga peternak kambing Peranakan Etawa (PE), umur peternak dan pendidikan terakhir peternak, rata-rata kepemilikan kambing PE. Jumlah produksi susu kambing PE dalam waktu satu hari dan harga jual rata-rata susu kambing PE perliter per hari.

\section{HASIL DAN PEMBAHASAN}

\section{Gambaran umum lokasi penelitian}

Desa Sungai Langka, Kecamatan Gedong Tataan, Kabupaten Pesawaran, Provinsi Lampung merupakan desa dengan masyarakat tingkat ekonomi menengah ke bawah yang sebagian besar mata pencahariannya dibidang peternakan, perikanan, dan pertanian.

Secara geografis, desa ini berdampingan yang dibatasi oleh sisi bagian Utara berbatasan dengan Desa Bernung, sisi bagian Timur berbatasan dengan Desa Kurungan Nyawa, sisi bagian Selatan berbatasan dengan hutan lindung register 19, sisi bagian Barat berbatasan dengan PTPN 7.
Luas wilayah desa ini 990 ha terdiri atas 10 dusun, kepala keluarga sebanyak 1501 dengan jumlah penduduk 5.036 jiwa yang terdiri dari 2.608 laki laki dan 2.428 perempuan, dan terletak di $1.500 \mathrm{~m}$ atas permukaan laut. Usaha peternakan yang paling banyak dilakukan oleh warga yaitu peternakan kambing PE sehingga Desa Sungai Langka dikenal juga sebagai daerah pengembangan peternakan kambing PE di wilayah Lampung dengan produk andalannya berupa susu kambing (Badan Pusat Statistik,2000).

\section{Karakteristik rumah tangga responden}

Karakteristik rumah tangga responden yang meliputi umur, anggota rumah tangga, kepemilikan asset dan pengalaman beternak di tampilkan pada Tabel 1.

Tabel 1. Karakteristik Rumah Tangga responden

\begin{tabular}{|c|c|c|c|}
\hline \multirow[t]{2}{*}{ Karakteristik } & \multicolumn{3}{|c|}{ Kelompok ternak } \\
\hline & $\begin{array}{c}\text { TunasMuda } \\
(\mathrm{n}=18)\end{array}$ & $\begin{array}{c}\text { Sehati Jaya } \\
(\mathrm{n}=13)\end{array}$ & $\begin{array}{c}\text { Margarini } 6 \\
(\mathrm{n}=9)\end{array}$ \\
\hline A.Umur & $38,55 \pm 5,94$ & $40,0 \pm 4,52$ & $42,89 \pm 4,64$ \\
\hline \multicolumn{4}{|c|}{ B. Jumlah anggota rumah tangga } \\
\hline$<5$ tahun & $1,00 \pm 0,06$ & $1,46 \pm 0,96$ & $0,77 \pm 0,09$ \\
\hline $13-18$ tahun & $1,00 \pm 0,09$ & $1,07 \pm 0,86$ & $1,33 \pm 0,86$ \\
\hline$>25$ tahun & $1,83 \pm 0,33$ & $2,07 \pm 0,86$ & $1,94 \pm 0,23$ \\
\hline \multicolumn{4}{|l|}{ C. Kepemilikan Aset } \\
\hline Sepeda Motor & $18(100 \%)$ & $13(100 \%)$ & $9(100 \%)$ \\
\hline Mobil & $0(0 \%)$ & $0(0)$ & $0(0 \%)$ \\
\hline Sepeda & $7(38 \%)$ & $8(61,5 \%)$ & $2(22,2 \%)$ \\
\hline Televisi & $18(100 \%)$ & $13(100 \%)$ & $(88,88 \%)$ \\
\hline Telepon & $(100 \%)$ & $(100 \%)$ & $8(88,88 \%)$ \\
\hline Computer & $2(11,11 \%)$ & $(15,38 \%)$ & $2(22,22 \%)$ \\
\hline Lemari es & $11(61 \%)$ & $9(69,2 \%)$ & $6(66,66 \%)$ \\
\hline \multicolumn{4}{|l|}{ D.Tingkat Pendidikan } \\
\hline SD & $2(11,11 \%)$ & $4(30,76 \%)$ & $2(22,22 \%)$ \\
\hline SMP & $7(38,88 \%)$ & $3(23,07 \%)$ & $5(55,55 \%)$ \\
\hline SMA & $7(38,88)$ & $3(23,07 \%)$ & $1(11,11 \%)$ \\
\hline \multirow[t]{2}{*}{ Perguruan Tinggi } & $2(11,11 \%)$ & $3(23,07 \%)$ & $1(11,11 \%)$ \\
\hline & $0(0 \%)$ & $0(0 \%)$ & $0(0 \%)$ \\
\hline E. Lama beternak & $10,66 \pm 4,55$ & $8,61 \pm 4,53$ & $10,22 \pm 3,07$ \\
\hline
\end{tabular}

Hasil penelitian menunjukkan bahwa usia kepala rumah tangga yang menjadi responden di masing-masingdusun bervariatif. Usia kepala rumahtangga di Kelompok ternak Tunas Muda merupakan yang termuda dengan rata-rata berumur 38,55 $\pm 5,94$ tahun. Namun demikian, secara keseluruhan usia kepala rumah tangga di Desa Sungai Langka masih tergolong produktif. Menurut BPS (2000), umur produktif dikategorikan bagi mereka yang berusia 15 hingga 64 tahun. Sedangkan mereka yang berusia kurang dari 5 tahun atau lebih dari 64 tahun diklasifikasikan sebagai umur tidak produktif. Hasil penelitian ini sejalan dengan hasil investigasi Yustika (2003) yang 
menemukan bahwa struktur populasi di daerah pedesaan Indonesia secara umum didominasi oleh kepala rumah tangga yang masih berusia produktif. Kondisi ini sangat ideal untuk mendukung aktivitas dalam memenuhi kebutuhan ekonomi rumah tangga jika usia kepala rumah tangganya masih tergolong produktif.

Terkait dengan kepemilikan aset, sebagian besar responden memiliki sepeda motor, sepeda, dan televisi. Kepemilikan aset bergerak berupa sepeda dan sepeda motor tersebut bisa mempermudah mobilitas responden dalam aktivitas sehari-hari khususnya dalam hal budidaya ternak sapi perah, misalnya sebagai sarana untuk mengangkut pakan hijauan maupun sebagai alat angkut pada saat menyetorkan susu segar ke tempat pengumpulan susu. Selain itu, sepeda motor juga berguna sebagai alat transportasi responden untuk bepergian dari dan ke luar wilayah Desa Sungai Langka. Kepemilikan televisi membuktikan bahwa responden juga terbuka dalam mengakses informasiinformasi yang bersifat visual. Selain sebagai media sumber hiburan, keberadaan televisi diharapkan bias menjadi media penyalur informasi teknologi dan pengetahuan baru yang berkaitan dengan usaha pertanian.

Hasil penelitian lainnya menunjukkan bahwa sebagian besar responden memiliki hand phone. Hal ini mengindikasikan bahwa sarana komunikasi bukan merupakan kendala bagi masyarakat di Desa Sungai Langka. Hanya sebagian kecil responden di Kelompok ternak Tunas Muda, Sehati Jaya dan Margarini 6 yang memiliki komputer yaitu masing-masing $11,11 \%, 15,38 \%$ dan 22,22\%. Sebagian besar dari ketiga kelompok ternak memiliki lemari es.

Tingkat pendidikan responden masih tergolong rendah. Hasil investigasi menunjukkan bahwa sebagian besar responden berpendidikan SD dan hanya sedikit responden yang menamatkan pendidikannya di jenjang yang lebih tinggi seperti SMA dan perguruan tinggi. Rendahnya tingkat pendidikan responden berhubungan dengan fakta bahwa jumlah infrastruktur sekolah di lokasi penelitian sangat terbatas. Hasil observasi menunjukkan bahwa hanya terdapat 2 sekolah dasar di lokasi penelitian sehingga penduduk yang ingin melanjutkan pendidikan ke sekolah lanjutan harus menempuh jarak yang cukup jauh di luar Desa Sungai Langka yakni di pusat Kecamatan Gedong Tataan yang berjarak lebih kurang 12 $\mathrm{km}$. Hal ini menyiratkan bahwa jarak tempuh yang jauh bias menyebabkan keengganan bagi responden untuk melanjutkan sekolah ke jenjang yang lebih tinggi. Dampaknya, tingkat pendidikan yang rendah seringkali mengakibatkan keterbatasan akses terhadap informasi

Responden termasuk peternak kambing perah yang berpengalaman dimana lama beternak responden paling sedikit 8,61 \pm 4,53 tahun di kelompok ternak Sehati Jaya dan yang paling lama adalah 10,66 \pm 4,55 tahun di Kelompok ternak Tunas Muda. Murray- Prior et al. (1999) menyebutkan bahwa petani yang telah berpengalaman dan cenderung memiliki tingkat pendidikan formal yang rendah seringkali enggan memperbarui keterampilannya karena mereka sudah merasa puas dengan keterampilan yang dimiliki. Hal ini tentu saja bisa menjadi penghambat bagi proses adopsi dan difusi inovasi teknologi baru.

Hasil penelitian menunjukkan bahwa laki-laki (suami) mendominasi kepemilikan kambing sapi perah di kelompok Ternak Tunas muda; Sehati Jaya dan Margirini 6 dibandingkan dengan wanita (istri). Tercatat hanya 1 orang wanita di kelompok ternak Tunas Muda dan Sehati Jaya sehingga persentasenya masing- masing adalah 5,5\% dan 7,69\%. Di kelompok Margarini 6 semua kepemilikan kambing perah di dominasi oleh laki-laki (suami). Hasil penelitian ini sejalan dengan penelitian Chawatama et al (2003) di Zimbabwe yang menunjukkan bahwa laki-laki lebih superior dibandingkan wanita dalam hal kepemilikan ternak kambing. Dominasi pria dibandingkan wanita membuktikan bahwa budaya patrialistik masih kental di lokasi penelitian. Hasil penelitian lainnya menunjukkan bahwa jenis kambing perah yang dipelihara oleh responden di Desa Sungai Langka adalah Kambing Peranakan Ettawah.

Rata-rata kepemilikan kambing perah responden bervariasi (Tabel 2) yaitu pada kelompok ternak Tunas Muda 9,22 \pm 5,20; kelompok ternak Sehati Jaya 8,53 $\pm 5,63$; dan di kelompok ternak Margarini 6 8,55 \pm 6,54. Jumlah kepemilikan ternak kambing perah di Desa Sungai Langka tergolong cukup banyak mengingat petani subsisten di Indonesia ratarata memiliki ternak kambing berkisar antara 13 ekor per rumah tangga (Nugroho 2010). Banyaknya kepemilikan kambing perah responden sejalan dengan ketersediaan lahan pertanian di Desa Sungai Langka khususnya berupa tegalan dan kebun yang seluas 6.473 hektar.

Ketersediaan lahan tegalan dan kebun tersebut memberikan peluang bagi responden untuk akses terhadap pakan hijauan. Selain menanam sendiri hijauannya, sebagian besar 
responden juga mencari hijauan di pinggir sawah, lapangan, pinggir sungai, dan pinggir jalan sebagai tambahan. Hasil survey menunjukkan bahwa rata-rata produksi susu kambing perah responden yang tertinggi berada di kelompok Ternak Tunas Muda yakni 2,22 \pm 0,11 liter/hari dan paling rendah terdapat di Kelompok ternak Margarini 6 sebesar 1,88 $\pm 0,19$. Sejalan dengan banyaknya kepemilikan kambing perah responden, jumlah rata-rata produksi susu segar di Desa Sungai Langka juga tergolong banyak. Hal ini mengindikasikan bahwa komposisi ternak Kambing perah responden banyak yang masih tergolong laktasi.

Tabel 2. Kepemilikan kambing perah

\begin{tabular}{|c|c|c|c|}
\hline \multirow[b]{2}{*}{ Karakteristik } & \multicolumn{3}{|c|}{ Kelompok Ternak } \\
\hline & $\begin{array}{c}\text { Tunas Muda } \\
\mathrm{n}=18\end{array}$ & $\begin{array}{c}\text { Sehati Jaya } \\
n=13\end{array}$ & $\begin{array}{c}\text { Margarini } 6 \\
n=9\end{array}$ \\
\hline $\begin{array}{l}\text { A. Yang } \\
\text { memiliki } \\
\text { kambing }\end{array}$ & & & \\
\hline Suami & $17(94,44 \%)$ & $11(84,61 \%)$ & $9(100 \%)$ \\
\hline Istri & $1(5,5 \%)$ & $1(7,69 \%)$ & 0 \\
\hline Anak & 0 & 0 & 0 \\
\hline Lainnya & 0 & $1(7,69 \%)$ & 0 \\
\hline $\begin{array}{l}\text { B.Jumlah } \\
\text { Kepemilikan } \\
\text { Kambing perah } \\
\text { (ekor) }\end{array}$ & $9,22 \pm 5,20$ & $8,53 \pm 5,63$ & $8,55 \pm 6,54$ \\
\hline $\begin{array}{l}\text { C. Jumlah } \\
\text { produksi susu } \\
\text { (liter/hari) }\end{array}$ & $2,22 \pm 0,11$ & $2,07 \pm 0,15$ & $1,88 \pm 0,19$ \\
\hline $\begin{array}{l}\text { D. Harga Jual } \\
\text { Susu (Rp/Liter) }\end{array}$ & $24388 \pm 341$ & $23230 \pm 350$ & $25888 \pm 802$ \\
\hline
\end{tabular}

Sumber: Data Primer (2016)

Terkait dengan harga jual susu segar, peternak mendapatkan harga jual bervariasi tergantung kualitas susunya. Uang hasil pembayaran susu segar diterima peternak setiap 10 hari sekali. Harga jual rata-rata susu segar yang diterima peternak di Desa Sungai Langka merupakan yang termahal, yaitu Rp. $25888 \pm$ 802 per liter di kelompok ternak Margarini 6 dan terendah adalah $\mathrm{Rp} 23230 \pm 350$ per liter di kelompok ternak Sehati Jaya.

\section{SIMPULAN}

Simpulan pada penelitian ini adalah :

1. Usia responden peternak di Sungai Langka di ketiga kelompok ternak, tergolong usia produktif, memiliki tingkat pendidikan yang rendah, cukup berpengalaman dalam beternak kambing perah dan sebagian peternak memiliki asset sepeda motor, sepeda dan televisi.
2. Laki-laki mendominasi kepemilikan kambing perah di semua kelompok ternak di desa Sungai Langka dengan rata-rata kepemilikan yang bervarasi mulai 9,22 \pm $5,20,8,53 \pm 5,63$ dan $8,55 \pm 6,54$

3. Jumlah produksi rata- rata susu kambing perah di kelompok ternak tunas Muda 2,22 \pm 0,11; kelompok ternak Sehati Jaya 2,07 \pm 0,15; dan kelompok Margarini 6 1,88 \pm 0,19 .

4. Harga jual susu kambing perah di masing kelompok ternak berbeda yaitu berkisar antara Rp.23230 sampai Rp. 25888.

\section{DAFTAR PUSTAKA}

Anonim, 2012. http://www.situspeternakan.com/2012/04/kambingperanakan-ettawa-pe.html di akses tanggal 23 Mei 2016.

Aka, R., I.G.S. Budisatria dan N Ngadiyono. 2008. Kinerja induk kambing peranakan Etawah pada pola pemeliharaan sistem kandang kelompok dan kandang individu di kecamatan Turi kabupaten Sleman. Buletin Peternakan Vol 32(3) hlm. 191 201.

Asmara Y , Sulastri dan I Haris.2013.Seleksi Induk Kambing PE berdasarkan Nilai Indeks Produktivitas Induk di Kecamatan Metro Selatan kota Metro. Jurnal Ilmiah Peternakan Terpadu Vol 1 No 3 Hal 5-8.

Badan Pusat Statistik. 2000. Keadaan Angkatan Kerja Indonesia. Badan Pusat Statistik. Jakarta.

Blakely dan Bade,1998. Ilmu Peternakan. Gadjah Mada University Press. Yogyakarta (Di Terjemahkan oleh Srigandono, B).

Chawarma, S, C.Mutisi and A.C. Mupawaenda.2003. The Socioeconomic status of Smallholder Livestock in Zimbabwe : A Diagnostic Study . Livestock Research for Rural Development, Volume 17, Artikel 143

Devendra dan Burns. 1994. Produksi Kambing di Daerah Tropis. Terjemahan IDK Harya Putra. Penerbit Institut Teknologi Bandung. Bandung.

Dinas Peternakan dan Kesehatan Hewan Provinsi Lampung.2011. Kambing Produk Unggulan Peternakan Lampung. Bandar Lampung.

Gustiani, E. dan S.I. Mulijanti. 2010. Budidaya ternak kambing PE di lahan bekas galian pasir dalam mendukung swasembada daging dan peningkatan ketahanan 
pangan. Pros. Seminar Nasional Teknologi Peternakan dan Veteriner 2010. Bogor 3 - 4 Agustus 2010. Puslitbang Peternakan. Bogor. hlm. 492 $-497$.

Murtidjo, B.A. 1993. Memelihara Kambing Sebagai Ternak Potong dan Perah. Kanisius. Yogyakarta.

Nugroho, E. 2010. Status sosial ekonomi peternak sapi perah di kecamatan Ponco kusumo Kabupaten Malang. J.Ternak Tropika Vol 12, No.2: 47-51,2011

Sarwono, B. 2001. Beternak Kambing Unggul.Penebar Swadaya. Jakarta

Sodiq, A. dan Z. Abidin. 2008. Meningkatkan Produksi Susu Kambing Peranakan Ettawa. Agro Media Pustaka. Edisi pertama. Jakarta.

Svalastoga, Kaare. 1989. Diferensiasi Sosial. Bina Aksara. Jakarta (Di Terjemahkan oleh Ali Mandau SU)

Yustika, A.E. 2003. Economic Analysis of Small Farm Households. PT Danar Wijaya -Brawijaya University Press Malang 